\title{
Suficiencia y acceso a servicios urbanos: la residencia reciente en eje Bogotá-Facatativá
}

\section{Sufficiency and access to urban services: new housing in the Bogotá-Facatativá axis}

\section{Tadeo Sanabria Artunduaga}

Fundación Universidad de América, Bogotá, Colombia.

tadeo.sanabria@investigadores.uamerica.edu.co

\section{John Ramírez Rios}

Fundación Universidad de América, Bogotá, Colombia.

\section{Resumen}

El presente trabajo examina los servicios urbanos que ofrecen soporte funcional a los proyectos de residencia nueva, localizados en las periferias urbanas y suelos rurales de los municipios que hacen parte del corredor industrial y de servicios Bogotá-Facatativá (CVSO) en Colombia. Para este efecto, se combina lo expresado por residentes, administradores de los conjuntos residenciales, constructores y funcionarios de las administraciones municipales, respecto a la disponibilidad y uso residencial de los servicios, con el análisis de los flujos entre las residencias y la oferta dotacional y sus coberturas. Los resultados revelan insuficiencias de atención a los primeros residentes, debidas a limitaciones en la entrega de servicios ofrecidos en la promoción inmobiliaria, ambigüedades en la regulación urbanística y el surgimiento tardío de una oferta complementaria en inmediaciones de los proyectos como respuesta a las nuevas demandas residenciales.

Palabras clave: Accesibilidad, servicios dotacionales urbanos, sistemas estructurantes del territorio.

\begin{abstract}
This paper explores the urban services that offer functional support to new residence projects, located in the urban peripheries and rural soils of the municipalities as part of the Bogotá-Facatativá industrial and services corridor (CVSO). For this purpose, it combines what is expressed by residents, administrators of the residential complexes, builders and officials of the municipal administrations, regarding the availability and residential use of the services, with the analysis of the flows between the residences, the public services. The results reveal insufficient attention to early residents, due limited services offered in real estate development, ambiguities in urban regulation and the late emergence of a complementary offer in the immediate vicinity of the projects in response to new residential demands.

Keywords: Accessibility, public urban services, structuring systems of the territory.
\end{abstract}

El proyecto de investigación Sistemas estructurantes y servicios de apoyo en vivienda de alta densidad no urbana en el corredor industrial y de servicios Bogotá - Facatativá. Aportes a la competitividad territorial, que derivó este artículo, fue financiado con recursos de la Fundación Universidad de América.

Documento recibido el 21 de mayo de 2019 y aceptado el 11 de diciembre de 2019.

Cómo citar: Sanabria, T. (2019). Suficiencia y acceso a servicios urbanos: la residencia reciente en eje Bogotá-Facatativá. Revista de Urbanismo, 41, 1-18. https://doi.org/10.5354/0717-5051.2019.54778 


\section{Introducción}

El crecimiento urbano planificado en Colombia está sujeto a la regulación contenida en la ley 388/97 de desarrollo territorial, la cual define unos procedimientos para asegurar que los suelos urbanizables incorporados cuenten con soportes urbanos suficientes, pero son los Planes de Ordenamiento Territoriales municipales (en adelante, POT) quienes clasifican y cualifican el suelo para determinar las áreas urbanizables donde se desarrollarán los nuevos proyectos de vivienda.

La utilización del suelo urbanizable programado en los POT, a través de planes parciales o bajo el mecanismo predio a predio, se concreta con el otorgamiento de las licencias urbanísticas y la salida a ventas de los proyectos de vivienda respectivos. Bajo las actuales condiciones normativas, cada proyecto ha de proveer un porcentaje de suelo en sistemas locales que, en conjunto con los sistemas generales provistos por el municipio y los servicios generados por un mercado restringido garantizarían su suficiencia funcional.

Ello significa que el crecimiento urbano apalancado en el desarrollo de los nuevos proyectos de vivienda implicaría un crecimiento proporcional de estos soportes. La hipótesis plantea que el crecimiento de la ciudad bajo los mecanismos compensatorios aplicados a los nuevos proyectos inmobiliarios garantizaría la suficiencia del soporte funcional a la ciudad. Esta hipótesis se revisa en los municipios que conforman el Corredor Industrial y de Servicios Bogotá - Facatativá (en adelante, CVSO), sector que ha visto un incremento de suelo urbanizable en sus POT, justificado por las proyecciones de residencia local, pero especialmente porque reporta una reciente intensificación de las áreas destinadas a la vivienda y a las actividades económicas.

El CVSO, es un eje funcional de integración regional, incluido en todas las fallidas propuestas de área metropolitana de Bogotá ya que vincula los municipios de la provincia de Sabana de Occidente que concentran la industria, los servicios logísticos, configurando el tercer

\footnotetext{
${ }^{1} \mathrm{Si}$ bien el Estudio de Huella urbana, convocó un grupo de expertos para sus estimaciones, estas cifras se basan en las proyecciones elaboradas por el Departamento Administrativo Nacional de Estadísticas DANE, que
}

mercado del Departamento de Cundinamarca y uno de los puertos secos más importantes de Latinoamérica.

En efecto, el Informe Final Cualitativo de 19 municipios de Cundinamarca señala que, en 2010, el CVSO se consolidó como el tercer mercado del Departamento al concentrar el $18,8 \%$ de su producción, y concluye: "La información cualitativa recopilada sugiere una dinámica particular en los municipios de Mosquera, Funza y Madrid; foco de la llegada de empresas ya constituidas en Bogotá, que por disponibilidad de suelo o ventajas tributarias han decidido trasladarse" (CCB, 2015, p. 73). Por otro lado, ofrece algunas cifras para afirmar que "Las estrategias de atracción de población y los intereses inmobiliarios de las entidades territoriales, han generado un fenómeno de aglomeración de población a lo largo de la Región" (CCB, 2015, p. 139).

Al revisar la participación de estos municipios en el incremento poblacional regional entre los años 2010 y 2016, según las cifras reportadas en el estudio de Huella Urbana (IDOM, 2018) ${ }^{1}$, se destaca el rápido crecimiento de los municipios de Mosquera y Madrid, los cuales duplican su población en estos 6 años, mientras los municipios de Funza y de Facatativá, estarán cerca de hacerlo en el año 2032. También revelan que dinamismo demográfico se muestra más activo sobre los ejes de la calle 80 y la calle 13 , donde se evidencia que los flujos económicos que se mueven en esos corredores van aparejados con una oferta creciente de proyectos de vivienda nueva y que este crecimiento es relativamente reciente.

Sin embargo, el incremento de la población ha significado un aumento de las áreas de vivienda, pero no necesariamente un incremento proporcional de soportes funcionales de los municipios. En tal medida, los servicios de soporte no son claramente provistos en el municipio donde se localizan y las cantidades pudieran ser insuficientes frente a las demandadas (Isaza, 2008; Preciado, 2012).

Los análisis de este estudio hacen referencia de manera específica a los servicios dotacionales y al sistema

muestra diferencias significativas con los datos publicados, aún no desagregados por municipio del censo nacional de población del 2018. 
de equipamientos, definido como el conjunto de todos los servicios dotacionales de carácter público, que la comunidad estima imprescindibles para el funcionamiento de su estructura social (Hernández, Alguacil, Medina y Moreno, 1997), "son una expresión de la socialización del espacio urbano, ya que la existencia deficiente de los mismos indica la inversión del capital social en lo urbano, explica la insuficiencia de esta inversión y su direccionamiento social selectivo" (IERU, 1999, p. 2). En ese sentido, la suficiencia y el acceso a ellos, a través de los sistemas generales, sistemas locales y por acción del mercado, son indicativos de la calidad de vida urbana.

Pero además, aportan a la competitividad urbana, noción vinculada a la existencia o creación de capitales territoriales y recursos locacionales que generan economías de escala y alcance para firmas y sectores (Cagmani, 2002; Sobrino, 2005), ya que la existencia de sistemas de soporte funcional asociado a la vivienda, no solo permite la retención de los flujos de población al asegurar una infraestructura para la satisfacción de sus necesidades básicas, sino la capacidad de atracción para nuevos consumidores, trabajadores e inversionistas, al incrementar el número de los negocios que atienden las nuevas concentraciones de la demanda. Sin embargo, para que ello suceda, es necesario que los servicios provistos por los sistemas de soporte sean accesibles, proporcionales y pertinentes a la población residente.

Por lo anterior, este estudio busca comprender nuevas dimensiones de la ocupación en áreas de crecimiento urbano y su forma de operar frente a la provisión de su soporte funcional. Para ello, a partir de la aplicación de instrumentos de consulta en un muestreo georreferenciado de los proyectos de vivienda reciente del CVSO, analiza la suficiencia y accesibilidad a los sistemas de soporte dotacional, bajo el entendido que la suficiencia alude a una valoración de la capacidad de la oferta para dar cuenta de un mínimo indispensable o deseable de bienes y servicios para la reproducción cotidiana (Cervio y D’Hers, 2012). En este caso, referido a las necesidades materiales de los residentes de los proyectos recientes de vivienda, en tanto la accesibilidad, es un concepto que expresa la facilidad de utilizar los servicios urbanos en condiciones igualitarias y sin exclusiones (Ortiz y Garnica, 2008) y refleja la fricción espacial producto de la separación entre actividades e individuos en cuya medición participan los costos y esfuerzos para superar las distancias entre la demanda, donde se origina la necesidad de un servicio, y la oferta, los destinos de atención de esa necesidad (Troncoso y Marmolejo, 2010).

\section{Sistemas estructurantes y servicios urbanos en la lógica urbanística del plan territorial.}

Desde un enfoque estructuralista, es posible comprender la ciudad por las relaciones entre sus partes, lo cual conduce a una interpretación de su organización a partir de la disposición de sus objetos constitutivos y de sus relaciones. Así, "La noción de estructura presupone que la ciudad está regida por un orden determinado y ella constituye la organización esencial que lo rige" (Munizaga, 2000 , p. 176). Webber (1970), asociaba ese orden a variables morfológicas y funcionales de elementos urbanos reconocidos tales como el sistema vial, los espacios verdes, equipamientos y los tramados. Un orden individual impuesto en un ámbito colectivo (García, 2016) cuya distribución es particular en cada ciudad, pero presente en todas ellas.

Milton Santos (1997), por su parte, aporta la concepción del territorio como un conjunto indisociable de sistemas de objetos y de acciones, al que Dávila, Munévar y Giraldo (2017) añaden una representación del espacio que otorga sentido a las prácticas territoriales. Así, los sistemas de objetos están dotados de una intencionalidad conferida por el sistema de acciones, de tal forma que cada sistema puede ser independizado como un conjunto de objetos que operan solidariamente, contribuyendo a garantizar un conjunto de acciones particular.

Estas dos aproximaciones, permiten comprender los sistemas estructurantes del territorio: una estructura, que expresa la configuración del conjunto de objetos de una ciudad en un todo orgánico compuesto por varios niveles de agregación y unos sistemas que expresan las relaciones entre esos objetos para garantizar su funcionamiento.

La identificación de esos sistemas es un punto aún de discusión, donde es crucial el criterio de organización utilizado. Algunos autores los clasifican en sistemas estructurantes naturales y artificiales; otros, los definen en topologías aerales y redéticas (Boix, 2003), y otro grupo de autores los refieren a los sistemas de objetos que 
abastecen los insumos que requieren sus habitantes para las actividades que desarrollan en el territorio; por lo tanto, solo incluye los sistemas dispuestos con la intencionalidad específica de soportar el suministro de bienes y servicios para la satisfacción de necesidades individuales y colectivas. Los sistemas estructurantes así concebidos son: los sistemas de servicios públicos, de movilidad, de espacio público y de equipamientos.

Estos cuatro sistemas estructurantes, coinciden en los desarrollos del derecho urbano de origen francés, con los denominados sistemas generales y locales, destinados por el Plan a proveer el soporte dotacional a los tejidos residenciales y productivos de la ciudad. Es el enfoque adoptado en la legislación urbanística colombiana para distinguir al responsable de financiar el crecimiento urbano, derivando los esquemas de cargas generales y locales. Los sistemas estructurantes son producto de proyectos municipales financiados por el Estado (sistemas generales) o generados por el urbanismo privado $y$ transferidos al dominio público (sistemas locales).

Pero el mismo criterio, de suministro de bienes y servicios para la satisfacción de necesidades individuales y colectivas como soporte a la actividad urbana, que aplica al sistema estructurante de equipamientos, puede englobar objetos urbanos de dominio, gestión y uso privado.

Estos servicios dotacionales, constituyen también soportes urbanos a la actividad residencial e imprimen funcionalidad a los territorios, pero a diferencia de los sistemas generales y locales, continúan siendo de dominio privado, su producción y distribución genera renta y se desarrollan en un suelo ya soportado por sistemas estructurantes (Sanabria y Ramírez, 2019). Se trata de la oferta de bienes, servicios y empleos que configuran las estructuras productivas de la ciudad.

Desde la teoría económica, esta distinción, define que los bienes y servicios privados son exclusivos y rivales, toda vez que se paga por ellos en virtud de su escasez y las partes consumidas por unos no pueden ser consumidas por otros. Su acceso entonces está en función de la capacidad de pago y de una oferta de servicios dotacionales que surge en proporción a la demanda y por tanto, a la concentración de consumidores. Así, la dotación en la misma área será mayor cuanto mayor sea la densidad, aun cuando los costos y calidad de los urbanismos conseguidos en una u otra densidad pueden variar significativamente.

Las infraestructuras que ofrecen estos servicios complementan los sistemas estructurantes y su operación es regulada en el ordenamiento territorial local con la indicación expresa de la posibilidad de localizarse en unas zonas, pero no en otras, de acuerdo a los impactos urbanísticos que genera. Así, una tienda de barrio puede localizarse en áreas residenciales pues es deseable su operación allí, mientras una estación de combustibles no, porque entraña riesgos a la población allí localizada.

\section{Los proyectos de vivienda nueva en el crecimiento urbano del eje Bogotá - Facatativá}

El estudio de Huella Urbana (2018) adelantado por la Empresa de Consultoría Ingeniería, Dirección de Obras y Montaje [IDOM] y la Gobernación de Cundinamarca, reportó 226 proyectos de vivienda nueva en 18 municipios vecinos de Bogotá, 59 de los cuales, se ubicaban en los municipios de Funza (13), Madrid (18), Mosquera (15) y Facatativá (13). Estos 59 proyectos fueron coincidentes con el inventario de proyectos de vivienda realizado por esta investigación. Sin embargo, la mayor parte de ellos son desarrollados en varias etapas que se identifican por los promotores como proyectos de venta, con lo cual esta cifra asciende a la suma de 160 proyectos en desarrollo, recientemente terminados o con aviso de ventas.

Del total de estos proyectos, 76 consumen 150 ha de suelo urbano, de manera particular en sus periferias, 67 se localizan en suelo de expansión urbana con un consumo de suelo de 330 ha y 17 utilizan 158 ha de suelo rural y suburbano.

Para este estudio, interesan los proyectos de vivienda localizados en suelo rural-de acuerdo a la clasificación del suelo municipal según sus POT-, por lo que es necesario hacer las siguientes aclaraciones:

La ley 388/97 y los decretos que reglamentan la figura del Plan Parcial y regulan las actuaciones para la urbanización e incorporación de predios en suelo urbano y expansión, establecen que los nuevos suelos se incorporan al suelo urbano una vez se realicen las obras de urbanismo; es decir que no es suficiente con la adopción de los planes parciales para ser catalogados como urbanos. En tal sentido, todos los proyectos que no han culminado sus procesos de urbanismo y entregado las 
cesiones correspondientes, son considerados en este estudio como desarrollos en suelo rural. De otra parte, determina que los suelos suburbanos son una subcategoría del suelo rural.
Así, de las 661 ha que consumen los proyectos de vivienda nueva en los cuatro municipios, podemos afirmar que casi el $75 \%$, son desarrollados por fuera de los perímetros urbanos vigentes (84 proyectos). La Tabla 1 , muestra la participación de cada municipio del total de proyectos identificados como rurales:

\section{Tabla 1}

Participación de los proyectos de vivienda nueva en suelo rural.

\begin{tabular}{lcc}
\hline Código & Superficie de los proyectos $(\mathrm{Ha})$ en suelo rural y de expansión & \% suelo rural \\
\hline Facatativá & 47,30 & 9,49 \\
Funza & 2,43 & 0,49 \\
Madrid & 310,25 & 62,27 \\
Mosquera & 138,26 & 27,75 \\
Total & 498,23 & 100,00 \\
\hline
\end{tabular}

Fuente: Elaboración propia.

De estos proyectos, se seleccionó una muestra de siete proyectos de venta (etapas) para ser analizados, cuya localización se observa en la Figura 1:

- Facatativá: Proyecto Ciudadela Parque Girasoles Reservado.

- Madrid: Quintas de Zaragoza, Hacienda Madrid El Prado y Urbanización La Finca VI Etapa.

- Mosquera: Ciudadela Novaterra Nogal y Novaterra Ciprés.

- Funza: Torres de Zuane. Alcaparros 


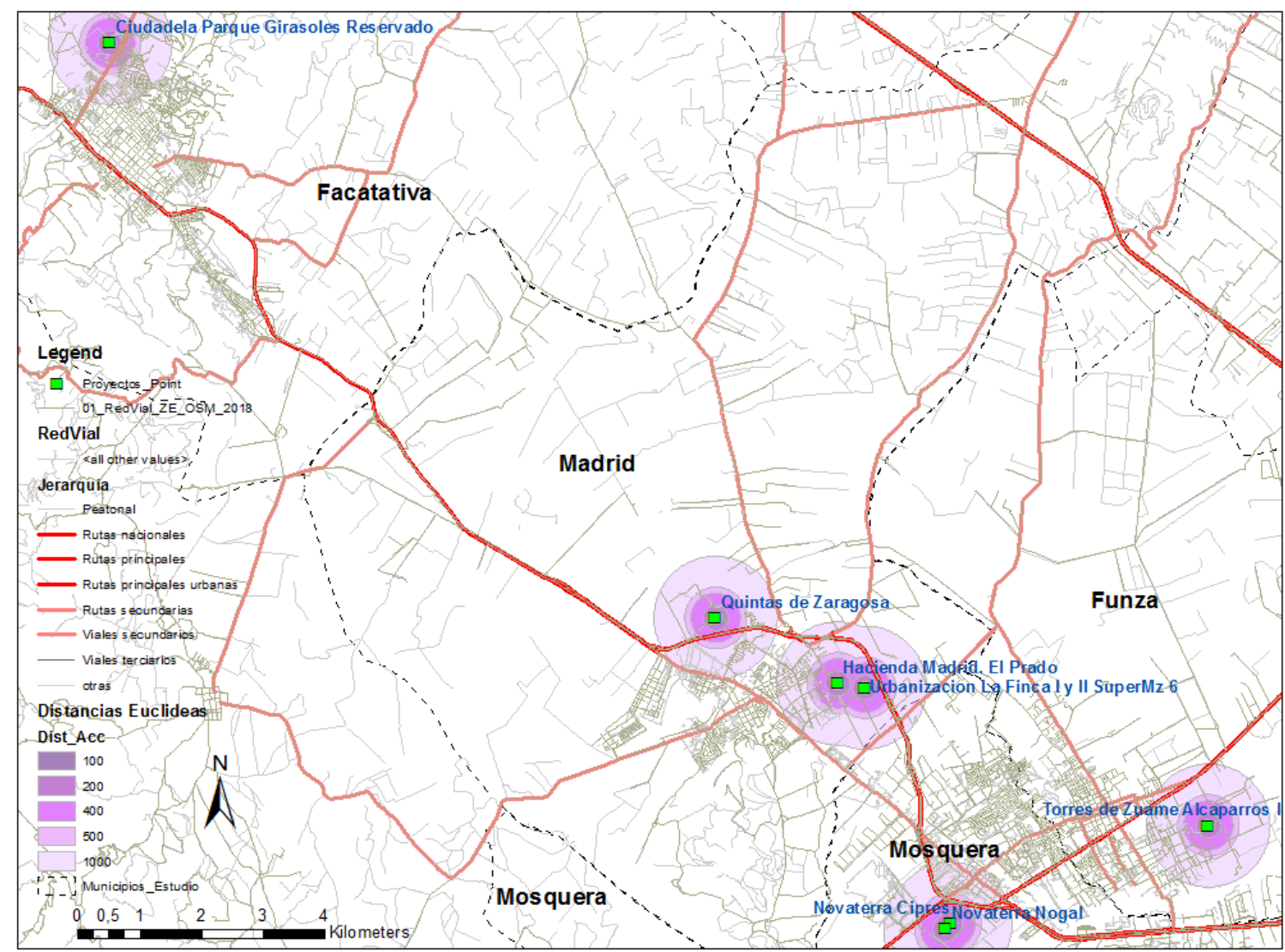

Figura 1. Localización de los Proyectos muestreados en el CVSO. Fuente: Elaboración propia.

\section{Métodos}

Por tratarse de proyectos de reciente ocupación, los registros documentales son escasos y de estar disponibles, presentan un escenario de ocupación futura: Los planes urbanísticos muestran los desarrollos que prevén las administraciones municipales o inversionistas privados, las licencias de urbanización aprobadas reflejan proyecciones particulares en ajuste a esos planes y los catálogos de venta de las constructoras, muestran los diseños de los productos inmobiliarios antes de su construcción. Por su parte, los planos oficiales no reflejan la ocupación que hacen los nuevos residentes y menos aún sus dotaciones, pues la periodicidad de actualización no alcanza a registrarlas.

Como consecuencia, hay escasos medios para describir las facilidades con las que cuentan los primeros ocupantes de los proyectos, por lo cual fue necesario utilizar instrumentos de recolección primaria de datos en siete proyectos de los 84 identificados y actualizar las cartografías.
Bajo un muestreo no probabilístico (de conveniencia), para una población indeterminada, se aplicaron 80 encuestas de caracterización a residentes entre los meses de julio y agosto de 2018, con el fin de identificar los patrones de interacción espacial entre los miembros del hogar (entendido como el grupo de personas que dependen de una sola preparación de alimentos en una misma vivienda) y la disponibilidad y uso de servicios dotacionales.

De manera complementaria, la misma selección fue utilizada para las 11 entrevistas realizadas a administradores de los conjuntos residenciales y firmas constructoras entre los cuales, se encuentran tres de las grandes empresas inmobiliarias de Colombia: Prodesa, Constructora Bolívar y Amarilo, en adición a las realizadas a los funcionarios de planeación urbana de las administraciones de gobierno municipal de los municipios de Funza, Mosquera, Madrid y Facatativá.

Para dar cuenta de la suficiencia y acceso a los servicios urbanos, se plantearon tres análisis que combinan las 
condiciones cualitativas derivadas de las encuestas a residentes o extraídas de las entrevistas, con un análisis cuantitativo a partir de la georreferenciación de la oferta de equipamientos e infraestructuras que proveen los servicios urbanos no domiciliarios. Es decir, aquellos que implican el desplazamiento de las personas fuera del lugar habitual de residencia.

El primero, es un análisis de conectividad a escala regional. Para lo cual, la encuesta incluyó preguntas acerca del destino de los desplazamientos por trabajo y estudio. Actividades a las que los residentes dedican la mayor parte del tiempo fuera de su hogar y que podrían implicar los mayores desplazamientos. Los datos obtenidos, permitieron la elaboración de las líneas de deseo y las matrices origen- destino que fueron comparadas con los resultados obtenidos de las encuestas de movilidad realizadas por el Distrito Capital en los años 2011 y 2015 para precisar las dinámicas de interacción regional de los nuevos residentes y la infraestructura de movilidad asociada a esos movimientos.

El segundo análisis, de interacción local y vecinal, interrogó a los residentes y administradores de los siete conjuntos residenciales muestreados, acerca de la disponibilidad y el uso que hacían de los sistemas estructurantes y servicios, pero requirió la identificar, localizar y mapear los elementos que configuran dichos sistemas en el ámbito de influencia de los proyectos, así como las localizaciones residenciales.

El procesamiento de los datos con este fin requiere de la definición de tres elementos: el lugar de las unidades habitacionales, el lugar donde los miembros de ese hogar hacen uso de un servicio y las infraestructuras que permiten el desplazamiento desde su hogar hasta donde se localiza el servicio. Con ellos se realizó un geoprocesamiento de redes en ArcGIS, para identificar las áreas de servicio en función de las distancias recorridas en trayectos peatonales, cuyo resultado identifica los servicios y equipamientos que se localizan a distancias Manhattan ${ }^{2}$ consideradas accesibles. La medición de la accesibilidad definió como barreras las vías rápidas de doble calzada y los canales, y se calculó con el porcentaje de servicios alcanzados en el rango de distancia de $500 \mathrm{~m}$ sobre el total de servicios inventariados.

Finalmente, tras la digitalización de las áreas de interés de los proyectos, se comparó el registro de áreas de las coberturas urbanas frente a: las cargas urbanísticas reglamentadas, los valores referenciales de consumo de suelo sugeridos para Colombia por Sanabria (2017) y las manifestaciones expresadas por los residentes y administradores, para establecer su suficiencia y el retardo en el disfrute de las facilidades por parte de los usuarios finales.

\section{La accesibilidad regional. Sistemas de soporte para el acceso al trabajo y a los servicios urbanos.}

La matriz origen destino es un instrumento que permite identificar los flujos funcionales a partir de encuestas y registros de movimientos de pasajeros, al relacionar los orígenes y destinos de los viajes generados en una zona específica.

Para observar las interacciones funcionales de los hogares e identificar el soporte infraestructural de que hacían uso para tener acceso al trabajo y a los servicios, se interrogó a los residentes acerca del destino de los viajes y los medios de transporte utilizados por los 214 miembros de los hogares encuestados, como muestra la Tabla 2, cuya georreferenciación permitió, construir la matriz origen-destino y las líneas de deseo.
2 Las distancias Manhattan, corresponden a las distancias más cortas recorridas desde un punto a otro por una red de calles existente; $A$ diferencia de las distancias geométricas, que miden la distancia de la línea más corta entre estos dos puntos. 
Tabla 2

Viajes Totales diarios según motivos indagados. (Trabajo y educación).

\begin{tabular}{|c|c|c|c|c|c|c|c|c|}
\hline \multirow{2}{*}{$\begin{array}{l}\text { Origen de los viajes } \\
\text { Proyectos }\end{array}$} & \multirow{2}{*}{$\begin{array}{c}\text { Funza } \\
\text { Zuame } \\
\text { Alcaparros }\end{array}$} & \multicolumn{2}{|c|}{ Mosquera } & \multicolumn{3}{|c|}{ Madrid } & \multirow{2}{*}{$\begin{array}{l}\text { Facatativá } \\
\text { Girasoles }\end{array}$} & \multirow{2}{*}{$\begin{array}{l}\text { Total } \\
\text { Total }\end{array}$} \\
\hline & & $\begin{array}{c}\text { Novaterra } \\
\text { Ciprés }\end{array}$ & $\begin{array}{c}\text { Novaterra } \\
\text { Nogal }\end{array}$ & $\begin{array}{c}\text { La Finca } \\
\text { VI }\end{array}$ & $\begin{array}{c}\text { Hacienda } \\
\text { Madrid } \\
\text { Prado }\end{array}$ & $\begin{array}{c}\text { Quintas } \\
\text { Zaragoza }\end{array}$ & & \\
\hline Total Trabajo & 22 & 20 & 19 & 17 & 23 & 15 & 16 & 132 \\
\hline Total Estudio & 6 & 12 & 17 & 8 & 16 & 12 & 0 & 82 \\
\hline Total General & 28 & 32 & 36 & 25 & 39 & 27 & 16 & 214 \\
\hline
\end{tabular}

Fuente: elaboración propia.

La participación de los viajes originados por trabajo o educación desde la zona de estudio que ilustra la Figura 2 , registra que el $53,69 \%$ de los viajes tienen como destino los municipios de la zona de estudio, el 37,93\% Bogotá y el 6.90 otros municipios. Con lo cual, poco más de la mitad de los viajes generados, se resuelven en la misma área de residencia y la mayor interacción de estos municipios, como es de suponer se establece con Bogotá.
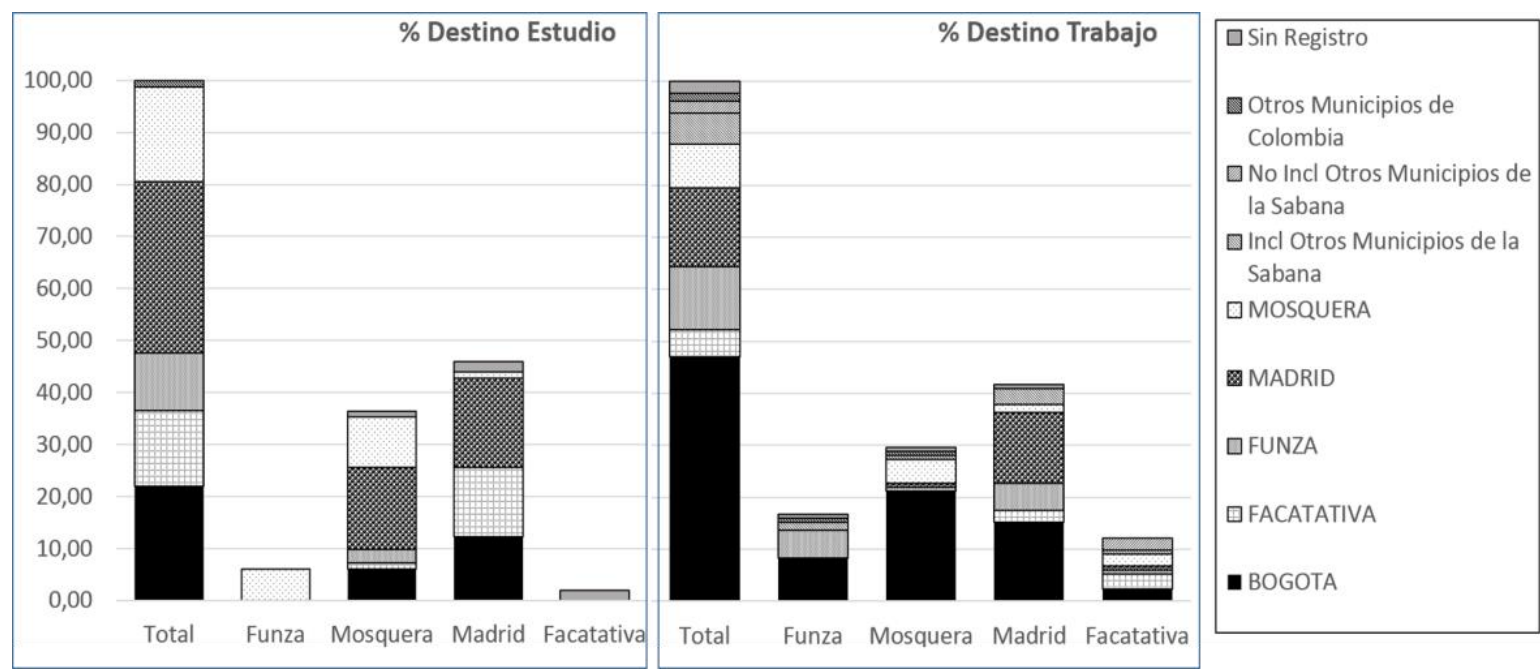

Figura 2. Destinos por municipio por motivación de trabajo y estudio. Fuente: Elaboración propia en base a Encuesta a residentes de nuevas urbanizaciones 2018.

Los municipios de Madrid y Mosquera son los más móviles concentrando casi el $80 \%$ de los desplazamientos del eje occidental. También muestra que cerca del 35\% de los residentes del municipio de Madrid, trabajan y estudian en el mismo municipio, seguido por Mosquera con el $20 \%$.

Otro aspecto destacable es la participación de Bogotá como destino de los viajes. Bogotá es el destino del $50 \%$ de los residentes del municipio de Mosquera, seguido por los de Funza con el 40\%, Madrid con el 33\% y Facatativá con el $18 \%$. Por otra parte, el municipio de la zona de estudio que concentra los destinos es Madrid al atraer el $7 \%$ de los viajes que se originan en otros municipios del eje, seguido por Mosquera con el 5,42\%.

En los años 2011, y posteriormente en 2015, la Secretaría de Movilidad de Bogotá SDM, realizó estudios de las dinámicas de movilidad, que incluyeron a los municipios que definen su ámbito de influencia regional. Para efectos de comparar estos resultados con los de la encuesta a residentes de este estudio, se tomó la matriz origen- destino (O-D) de viajes intermunicipales diarios 
que incluye los viajes internos y se ajustó de la siguiente manera:

- Se excluyeron, los viajes internos de Bogotá, ya que más del $90 \%$ de los viajes tienen como origen y destino la Ciudad de Bogotá.

- Se excluyeron los viajes cuyo origen fuera diferente a los cuatro municipios de la zona de estudio (Facatativá, Mosquera, Madrid y Funza), haciendo corresponder el origen de los viajes.

- Se revisó el factor motivacional de los viajes, ya que la matriz utilizada por la SDM, incluye todos los motivos de los desplazamientos, en tanto el nuestro, solamente indagó por trabajo y estudio.

- Se tomaron como valores de comparación de ambos estudios, los porcentajes de los viajes reportados y no el número de viajes brutos realizados.

- Se agruparon los destinos en ambos estudios así: 1. Bogotá, dada la incidencia de este destino en el total de los viajes; 2 . Los cuatro municipios de la zona de estudio fueron tratados de manera independiente; 3. Los destinos coincidentes en ambos estudios; 4. Los destinos localizados en la Sabana de Bogotá registrados en solo uno de los estudios y 5 . Los municipios fuera del área de influencia de Bogotá o de Sabana registrados en la encuesta para este estudio.

Para efectos de la interpretación de los resultados, se tiene en cuenta que el estudio de la SDP se realizó con una muestra de todos los hogares de los centros urbanos, en tanto en el presente estudio, el muestreo se realizó de manera exclusiva en hogares de reciente residencia de las periferias urbanas. La tendencia histórica de la interacción funcional expresada en los desplazamientos con origen en los cuatro municipios que constituyen el eje occidental, son ilustradas en la Figura 3. Esta muestra que los viajes a Bogotá se duplican desde 2011, alcanzando cerca del 40\% de los originados en la zona de estudio confirmando la interacción creciente de los municipios del eje occidental con Bogotá.

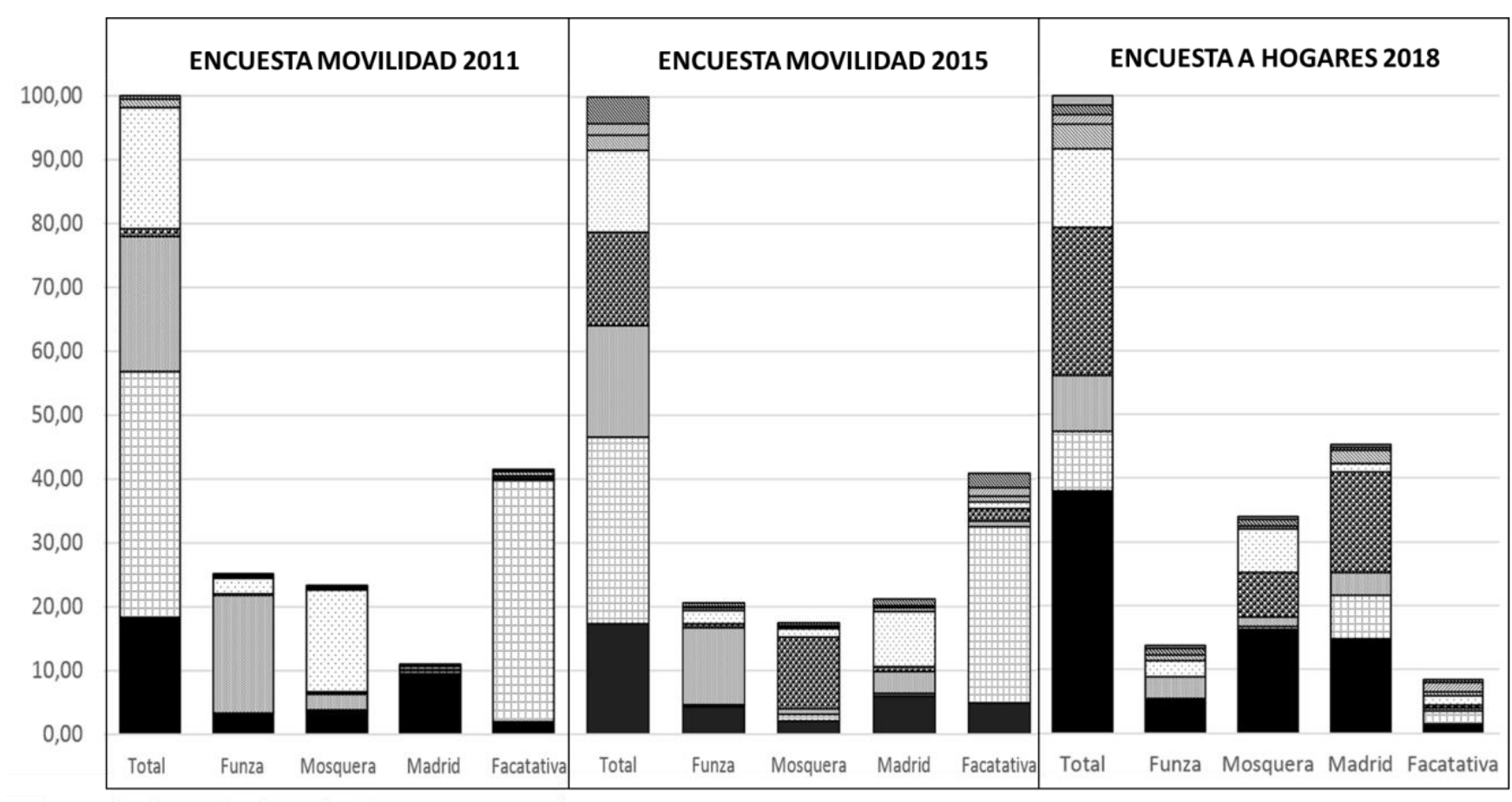

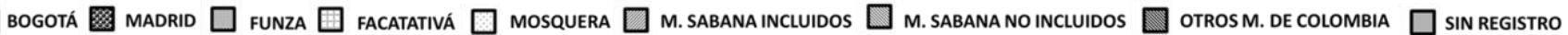

Figura 3. Destinos (Viajes Totales) por municipio en periodos de muestreo 2011, 2015 y 2018. Fuente: Elaboración propia basada en datos de Secretaría Distrital de Movilidad y la encuesta realizada a propósito de este estudio (2018). 
Los mayores crecimientos son registrados por Mosquera y Madrid con un incremento entre 2011 y 2018 del $10 \%$, y del $2 \%$ respectivamente. Los viajes entre Funza y Bogotá crecen ligeramente, en tanto los realizados desde Facatativá, registran un ligero descenso. Esta ciudad, muestra una tendencia fuertemente decreciente especialmente en los viajes internos, tendencia observada en menor grado en Funza. Se incrementa la interacción con Madrid y Mosquera ciudades que concentran de manera creciente los viajes desde el CVSO.

Los demás municipios de la Sabana muestran un ligero pero constante crecimiento como destino de los viajes, que se duplica en cada uno de los periodos considerados. El 4\% de los destinos de los viajes, corresponden a estos municipios cuyos mayores aportantes son los municipios de Madrid y Facatativá.

El Municipio más alejado de Bogotá (Facatativá) pierde protagonismo como receptor y originador de los viajes a esta ciudad, posición que es asumida por Madrid y Mosquera, ciudades que concentran los viajes internos. Lo anterior puede significar que estos últimos, han conseguido algún grado de autosuficiencia en la demanda de trabajo y oferta de estudio; y que, los movimientos intermunicipales originados en Madrid y en menor grado Mosquera y Funza, están relacionados con desarrollos empresariales derivados de proyectos productivos localizados sobre el eje, aunque no propiamente en ellos, como se confirma al sobreponer de los destinos con el mapa de usos regionales del Modelo Económico Territorial (Comité de Integración Territorial, 2018).

Ahora bien, la relación observada de los movimientos con las infraestructuras de movilidad, indica que los destinos de trabajo se concentran alrededor del eje vial que conecta el centro expandido de Bogotá con la Calle 13 y sobre el primer tercio de la conexión entre esta vía y la
Calle 80. Los viajes al centro histórico de Bogotá están asociados principalmente a la oferta de educación universitaria, mientras que los centros urbanos de los municipios del eje vinculan los de educación básica; lo cual, muestra una relación directa entre las distancias a los proyectos y complejidad de los servicios, confirmada por el análisis de interacción local.

\section{La accesibilidad local y el soporte a los servicios urbanos.}

Este análisis se orientó a establecer la accesibilidad local. Para ello, se tomó como fuente de la red de calles el servicio de datos abiertos Open Street Map (Wikiproyecto Colombia, 2018). Los datos de equipamientos y servicios dotacionales levantados a partir de las imágenes de Google Maps y Google Earth, fueron georreferenciados en un Sistema de Información Geográfica, cubriendo un radio geométrico de un kilómetro de distancia a partir del centroide de los siete proyectos muestreados en el estudio.

El análisis se realizó en dos pasos que consideraron la accesibilidad peatonal como la más eficiente debido a su autonomía direccional, a que o no depende de infraestructuras o sistemas complejos de movilidad y los recorridos están limitados por la fuerza motriz que permite el desplazamiento. Esto hace que la accesibilidad esté determinada por un corto rango de distancias que diversos estudios han estimado entre los 400 y 500 m. (Esquivel-Cuevas, Hernández y Garnica, 2014)

El primero de ellos, estableció las áreas de servicio de cada proyecto, para lo cual se definió como impedancia la distancia en metros lineales con rangos de proximidad accesible cada $100 \mathrm{~m}$ utilizando distancias Manhattan. El segundo, identificó los servicios localizados en cada rango de distancias, los cuales fueron clasificados en 13 categorías en función de necesidades residenciales así (ver Tabla 3): 


\section{Tabla 3}

Clasificación de servicios por periodicidad de uso

\begin{tabular}{|c|c|c|}
\hline $\begin{array}{l}\text { Servicios que atienden necesidades } \\
\text { frecuentes }\end{array}$ & Servicios de uso periódico & Servicios de uso contingente \\
\hline $\begin{array}{l}\text { Alimentos. supermercados, tiendas y cigarrerías } \\
\text { barriales, mercados verduleros, almacenes de } \\
\text { alimentos preparados, panaderías, pastelerías, } \\
\text { salsamentarías, carnicerías, distribuidoras de } \\
\text { huevos, carboneras, restaurantes, asaderos, } \\
\text { comidas rápidas, dulcerías, fruterías, heladerías, } \\
\text { pizzerías. }\end{array}$ & $\begin{array}{l}\text { Servicios Culturales o religiosos: centro de } \\
\text { artes, museos, teatros, iglesias y templos. }\end{array}$ & $\begin{array}{l}\text { Administración pública y servicios asistenciales } \\
\text { a población vulnerable: Alcaldía, fiscalía, } \\
\text { juzgados, notarias; centros de atención a la } \\
\text { familia, de tratamiento a la drogadicción, } \\
\text { jardines infantiles, guarderías, ancianatos, } \\
\text { servicios de empleo. }\end{array}$ \\
\hline $\begin{array}{l}\text { Artículos y servicios para el hogar. carpinterías, } \\
\text { cerrajerías, ferreterías, depósitos de materiales } \\
\text { de construcción, talleres de ornamentación } \\
\text { lavanderías, vidrierías, tapicerías, reparación de } \\
\text { electrodomésticos, remontadoras de calzado, } \\
\text { productos de aseo, veterinarias, viveros, } \\
\text { papelerías y fotocopias, cafés Internet, tiendas } \\
\text { de mensajería; almacenes de regalos, centros } \\
\text { comerciales, computadores, muebles, colchones } \\
\text { artículos de fotografía, disfraces, floristerías, } \\
\text { tiendas de deportes, librerías, cacharrerías, } \\
\text { talabarterías, misceláneas, pañaleras, } \\
\text { almacenes de ropa, calzado y artículos de } \\
\text { belleza, confecciones y modisterías; salas de } \\
\text { belleza, Spa y tatuajes. }\end{array}$ & $\begin{array}{l}\text { Entretenimiento: Centros artísticos, bares, } \\
\text { rockolas, cafeterías, licoreras, salones de juegos, } \\
\text { casinos, campos de tejo; coliseos, estadios, } \\
\text { salones de eventos. }\end{array}$ & $\begin{array}{l}\text { Servicios administrativos privados: Servicios de } \\
\text { asesorías y trámites contables, jurídicos e } \\
\text { inmobiliarias; seguros, cajas de compensación. }\end{array}$ \\
\hline $\begin{array}{l}\text { Educativos: centros educativos de capacitación } \\
\text { técnica y profesional, escuelas, colegios y } \\
\text { universidades y bibliotecas. }\end{array}$ & $\begin{array}{l}\text { Financiero: bancos, cajeros automáticos, } \\
\text { servicios de giros y pagos, prenderías. }\end{array}$ & $\begin{array}{l}\text { Seguridad: atención policial, cárceles, centros de } \\
\text { emergencias, estaciones de bomberos, defensa } \\
\text { civil. }\end{array}$ \\
\hline $\begin{array}{l}\text { Movilidad \& Mantenimiento vehículos: } \\
\text { accesorios, talleres y repuestos para autos; } \\
\text { montallantas, servicios de auto lavado, } \\
\text { bicicleterias, estaciones de combustible; } \\
\text { concesionarios, parqueaderos, puentes } \\
\text { peatonales, estaciones, agencias y terminales de } \\
\text { buses. }\end{array}$ & $\begin{array}{l}\text { Recreación \& deportes: parques, clubes } \\
\text { deportivos, atracciones mecánicas, canchas y } \\
\text { polideportivos. }\end{array}$ & $\begin{array}{l}\text { Servicios de Salud y funerarios: hospitales, } \\
\text { clínicas, centros médicos, laboratorios clínicos, } \\
\text { farmacias y funerarias. } \\
\text { Hospedaje: hoteles, hostales, moteles, refugios. }\end{array}$ \\
\hline
\end{tabular}

Fuente: elaboración propia.

Los resultados del análisis señalan que los bienes y servicios que se prestan en la vecindad peatonal inmediata son los de alimentación y asistencia al hogar, la mayor diversidad y cantidad de esta oferta se localiza entre los 200 y 300 m, a partir de los cuales se reduce, aunque crece en complejidad.

De los servicios localizados en el área de influencia de los proyectos, el $2,91 \%$, son accesibles peatonalmente, el $8,45 \%$, se ubican a distancias Manhattan superiores a 500 $\mathrm{m}$, pero inferiores a un $\mathrm{km}$ y el $88,6 \%$, a distancias mayores, requiriendo necesariamente medios de trasporte motorizado público o privado.
Pese a la limitación de los datos, el único proyecto que ha completado el número de etapas previsto es el proyecto Quintas de Zaragoza y la Ciudadela Parque en el Municipio de Facatativá, es el proyecto de mayor ejecución a la fecha. Si bien aún tiene suelo por desarrollar, ha terminado $y$ entregado las unidades correspondientes a ocho etapas, entre las cuales está la Ciudadela Parque Girasoles Reservado encabezando la accesibilidad a los servicios $(2,47)$. Es seguido por el proyecto La Finca en el municipio de Madrid $(0,74)$ que evidencia el segundo progreso en la ejecución de sus etapas (ver Figura 4) 
El proyecto Novaterra localizado en el municipio de Mosquera revela la más baja accesibilidad $(0,07)$ a la vez que la residencia más reciente y el nivel más bajo de ejecución, pues a la fecha de las encuestas, solamente había terminado las etapas Nogal y Ciprés de seis previstas que están en proceso de venta y dispone de suelo para el desarrollo de otras etapas. Además, es el único proyecto, cuyas etapas muestreadas no integran a su desarrollo proyectos de vivienda de interés social. Por su parte, la accesibilidad de los proyectos Zuame, Hacienda Madrid y Quintas de Zaragoza, oscila entre 0,20 y 0,27.

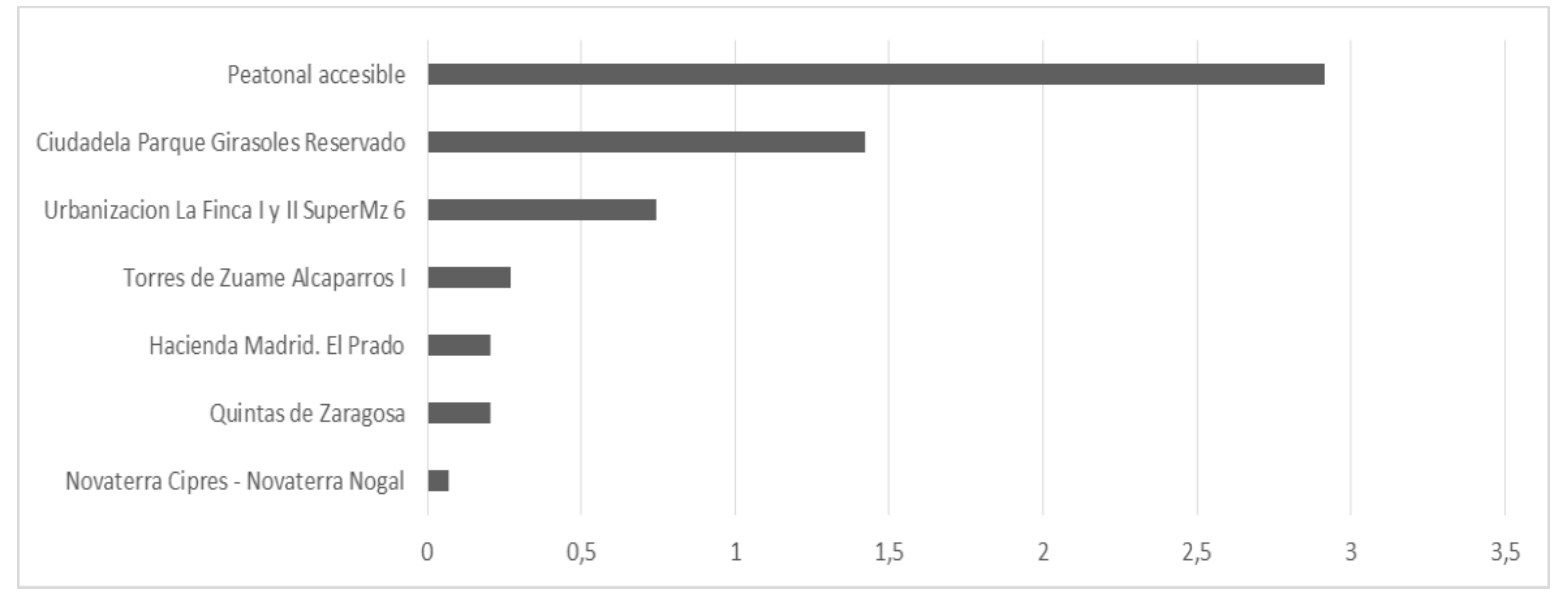

Figura 4. Accesibilidad total por proyecto. Fuente: Elaboración propia.

La accesibilidad total de estos siete proyectos fue de 2,91, pese a que en algunos de ellos es necesario superar autopistas de alta velocidad o transitar con condiciones de inseguridad y riesgo que limitan el acceso a algunos servicios, además, los resultados hacen evidente la relación directa entre el grado de consolidación del proyecto con la disponibilidad a los servicios.
La Figura 5, muestra la valoración de la accesibilidad respecto al carácter funcional de la oferta de servicios. Esta oferta es liderada por los servicios de alimentación, seguidos de lejos por los de movilidad, adquisición de bienes, asistencia al hogar, entretenimiento, salud, comunicaciones, financieros, educativos y los recreativos.

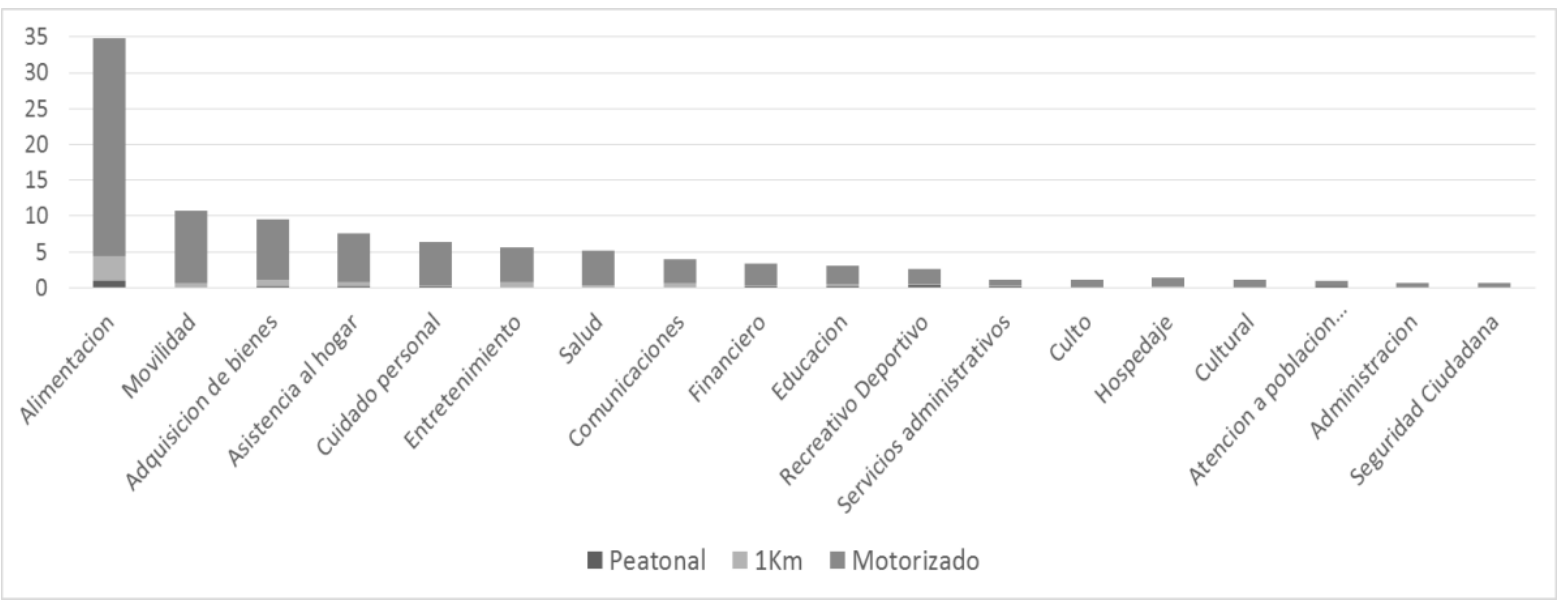

Figura 5. Accesibilidad local por función. Peatonal o motorizada. Fuente: elaboración propia. 


\section{Suficiencia y retardo en la entrega de las dotaciones}

A partir de las áreas desarrolladas por las siete etapas de los proyectos que constituyen la muestra y dado que los servicios previstos se vinculan a un proyecto mayor con la entrega de cesiones al municipio, para el cálculo de suficiencia fue necesario estimar la superficie de la etapa muestreada respecto del proyecto total. Exceptuando a
Quintas de Zaragoza, el desarrollo alcanzado por las etapas no supera el $40 \%$ y el promedio de ejecución del conjunto de proyectos se sitúa en el $24,01 \%$ de la superficie neta urbanizable privada (ANUP) y del $17,72 \%$ de suelos de soporte público. La Figura 6, representa los porcentajes de suelo que definen el sistema de cesiones ejecutadas por proyecto.

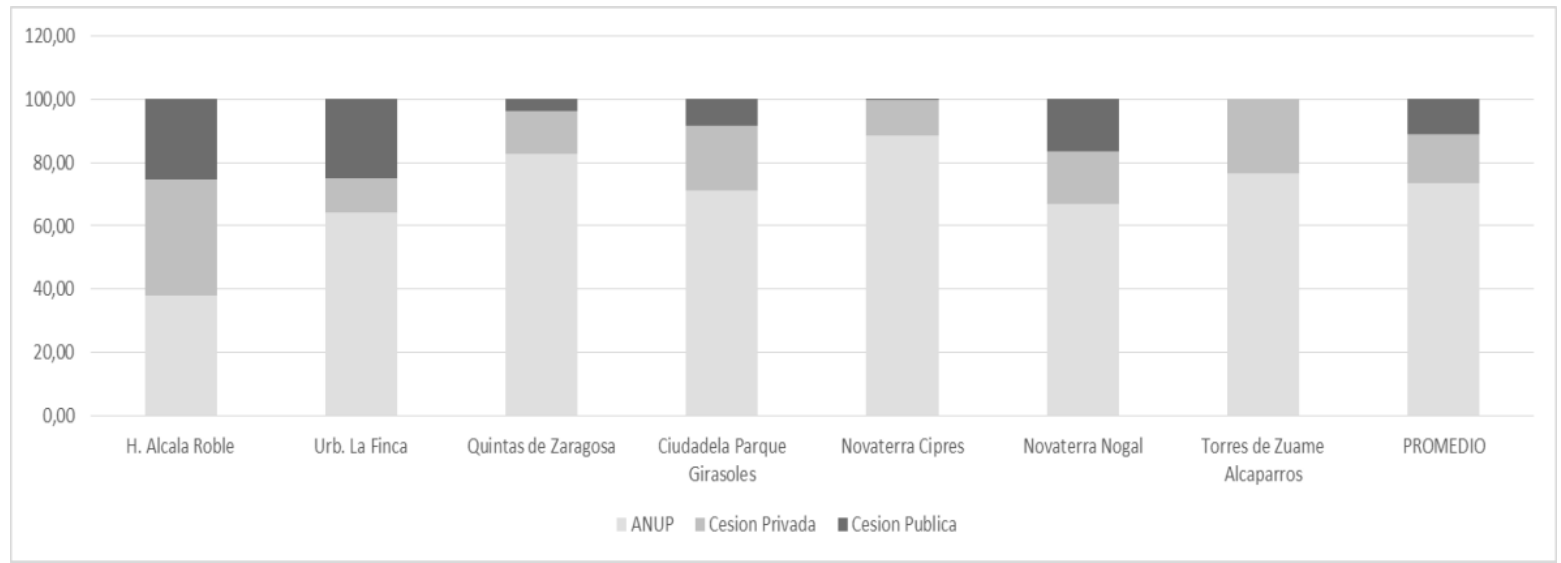

Figura 6. Porcentajes de cesiones respecto del suelo urbanizable por proyecto. Fuente: elaboración propia.

La población urbana de los 4 municipios suma 358.105 habitantes según proyecciones DANE. A 2018 y de acuerdo a los estándares propuestos por Sanabria $(2017)^{3}$, deberían hacer un consumo teórico de suelo urbanizable de 2.945 ha, de las cuales el $13 \%$ correspondería a espacio público, 7,3\% para equipamientos públicos y $18,5 \%$ para movilidad; constituyendo el suelo de soporte funcional $(39,07 \%)$.

Por su parte, las áreas destinadas a ofrecer ese soporte en los proyectos ocupan el $42,33 \%$. Las etapas muestreadas, con una participación del $10,63 \%$ de la superficie los proyectos y pese a su avance, solo han ejecutado el $1,94 \%$. Cinco veces menos de lo que se esperaría.

Al interior estas etapas, solamente tienen alguna representación, los servicios recreativos y alguna modalidad simple de aprovisionamiento para alimentación o mantenimiento del hogar, que complementan la oferta de servicios de los proyectos inmobiliarios, constituida por estacionamientos vehiculares, salones comunales, áreas de juegos y eventualmente jardines infantiles, gimnasios $\mathrm{y}$ áreas húmedas. De ellos, el que se muestra claramente insuficiente a pesar de dar cumplimiento a la regulación local, es el estacionamiento vehicular, en proporciones difícilmente superables, que obligan una ocupación irregular de las vías y del espacio público.

Por su parte, las cesiones públicas, asociadas al conjunto de proyectos urbanos que definen una promoción inmobiliaria, hacen su aporte con parques públicos y de manera excepcional, equipamientos de mayores magnitudes y complejidad. Estas cargas deben cumplir varias condiciones entre las que cabe destacar su tamaño, proporcional al suelo urbanizable disponible (entre el $25 \%$ y el $40 \%$ ) incluyendo vías, parques y equipamientos; y los estándares de espacio público

\footnotetext{
${ }^{3}$ Dichos estándares estimaron el consumo de suelo urbanizable por habitante con base en el registro de suelos consumidos por cada función urbana y de parámetros normativos o de diseño aplicables en Colombia.
} 
efectivo por habitante decididos por cada POT. Los demás servicios son operados de manera privada en los tejidos residenciales o productivos vecinos a los proyectos. De hecho, al revisar detenidamente el inventario de servicios generados según su función en toda el área de estudio, se observa que, con excepción de servicios recreacionalesdeportivos y administrativos, son provistos fundamentalmente por el mercado, no por los procesos de planificación formal.

El aprovisionamiento alimentario de los residentes se realiza mayoritariamente en tiendas de barrio $y$ supermercados vecinales $(58,7 \%)$ seguido de las grandes superficies comerciales (33\%). Por contraste, son muy poco usados los aplicativos de mensajería y domicilios.
Los equipamientos de mayor magnitud y complejidad se localizan en suelos no residenciales en el ámbito de influencia de los proyectos. Estos corresponden a áreas verdes cualificadas, centros comerciales, equipamientos y centros de empleo asociados a zonas de desarrollo logístico e industrial e incluyen a 17 colegios y centros de formación profesional; 65 unidades de atención a la salud, con un alto porcentaje de droguerías (36), centros de diagnóstico clínico, atención de especialidades médicas u odontológicas y un centro de salud privado. No obstante, el $81,7 \%$ de los servicios están localizados en suelo con usos residenciales.

\section{Tabla 4}

Servicios en suelos residenciales y no residenciales en el ámbito de influencia de los proyectos.

\begin{tabular}{lrrr}
\hline Ámbito Peatonal & No Residencial & Residencial & Total general \\
\hline Ciudadela Parque Girasoles Reservado & 8 & 53 & 39 \\
Hacienda Madrid. El Prado & 6 & 0 & 47 \\
Novaterra Ciprés - Novaterra Nogal & 2 & 0 & 5 \\
Quintas de Zaragoza & 2 & 26 & 13 \\
Torres de Zuame Alcaparros I & 1 & 13 \\
Urbanización La Finca I y II SuperMz 6 & 0 & 1048 & 14 \\
Fuera de Rango & 200 & $\mathbf{1 1 7 9}$ \\
\hline Total & $\mathbf{2 1 9}$ & $\mathbf{8 1 . 7}$ \\
\hline Porcentajes & $\mathbf{1 5 . 2}$ & 1443 \\
\hline
\end{tabular}

Definido en Plan Parcial u otro instrumento de planeación local. Fuente: elaboración propia.

El régimen de propiedad horizontal define así los bienes comunes esenciales: "Bienes indispensables para la existencia, estabilidad, conservación y seguridad del edificio o conjunto, así como los imprescindibles para el uso y disfrute de los bienes de dominio particular" (Ley 675 de 2001). Es decir, son los bienes de la copropiedad que necesariamente se deben entregar junto con la unidad de vivienda adquirida, ya que sin ellos no es posible habitarla. Sin embargo, con excepción de servicios públicos domiciliarios, estos no corresponden a los servicios que atienden las necesidades individuales de la población residente.
Por tanto, la entrega por parte de la constructora de las infraestructuras para los servicios ofrecidos en el proyecto se realiza cuando se completa la construcción y venta del $51 \%$ de los coeficientes de la copropiedad. Lo anterior, sumado a los tiempos que puede tomar la conformación de la administración de propietarios, la definición de mecanismos para recibir las áreas comunes y su transferencia a la copropiedad, hacen que el disfrute efectivo de estos servicios por los primeros residentes, sean limitados o impliquen una carencia temporal. Las encuestas a residentes revelan lo siguiente:

Los proyectos más recientes son Novaterra Ciprés y Novaterra Nogal en el municipio de Mosquera, con menos 
de un año de residencia; le siguen Torres de Zuame (Funza) y Hacienda Madrid El Prado (Madrid), con antigüedad inferior a tres años, y Quintas de Zaragoza, la Finca (Madrid), y Parque Girasoles Reservado en Facatativá, con residencia superior a los 3 años.

Hay un patrón similar en las preferencias para los lugares utilizados para actividades recreativas donde poco menos del $80 \%$ lo realiza en áreas libres y el resto en las zonas recreativas de los centros comerciales; Así mismo, cerca del $30 \%$ se recrea en parques cercanos del mismo municipio, $26 \%$ en parques de municipios vecinos y solo el $17 \%$ en las áreas habilitadas dentro del proyecto donde residen.

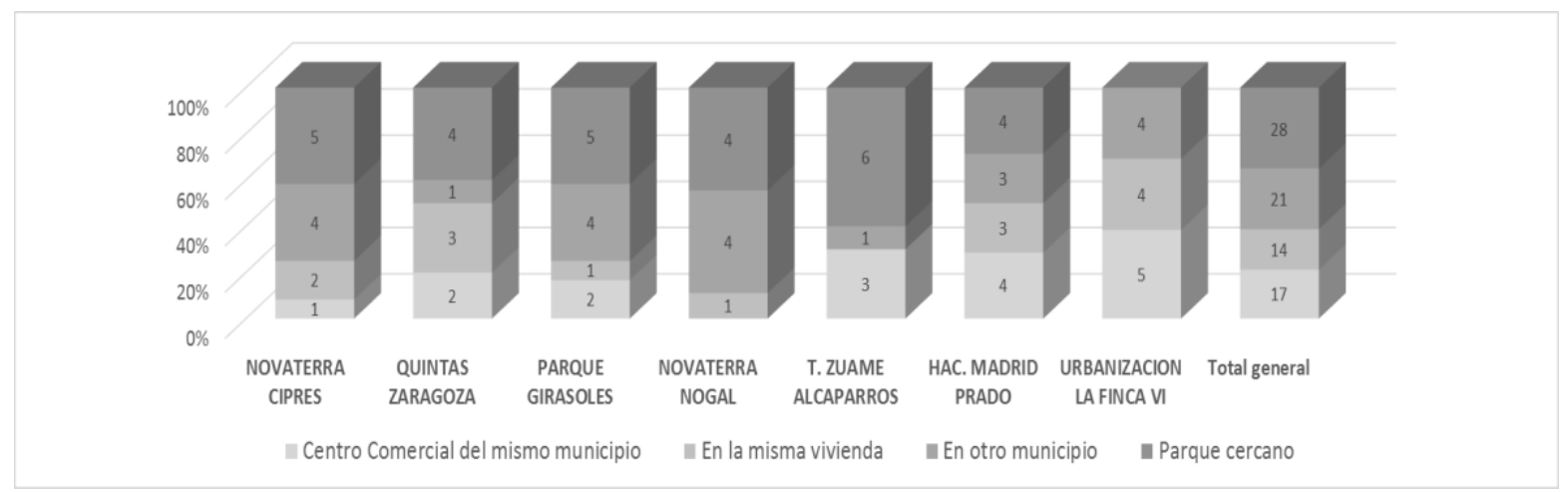

Figura 7. Preferencias para desarrollar actividades recreativas. Fuente: elaboración propia.

El mayor contraste se presenta con los proyectos La Finca y Torres de Zuame, ya que en el primero no utilizan parques cercanos, en tanto en el segundo no utilizan las zonas verdes del proyecto. En entrevista realizada al administrador de La Finca, expresaba categóricamente que no hay parques y las alternativas recreativas para los residentes solo permiten dar una caminata en los alrededores, la calle y un micro parque para los niños. Añadía que "el parque de las flores, es el más cercano pero yo creo que pocos los llevan allá, pues está lejos", lo que coincide con el análisis de accesibilidad a equipamientos que solo encontró para este proyecto, una reducida área en la categoría "Recreacional-Deportiva» en el rango de accesibilidad peatonal y otro en el rango de un kilómetro. Torres de Zuame por su parte, es de residencia muy reciente y sus áreas comunes están, de acuerdo a la entrevista a su administrador en proceso de entrega, por lo que "se utilizan con limitación".

Las entrevistas realizadas, permiten afirmar que existen dos condiciones que dificultan el acceso a los servicios ofrecidos especialmente al $50 \%$ de primeros propietarios: La primera, alude a la entrega de las zonas comunes a los propietarios, y la segunda a la puesta en servicio de las dotaciones ofrecidas en el proyecto que hacen parte de las cesiones públicas obligatorias. Esto entraña el retardo en la entrega y conflictos de responsabilidad sobre la propiedad:

Por una parte, relacionados con el cuidado, mantenimiento y usufructo de las zonas comunes de la etapa antes de ser recibidas por la copropiedad. Lo mismo ocurre con las zonas públicas producto de cesiones obligatorias, pero agravado porque la entrega la realiza el constructor a la alcaldía municipal en plazos mayores y solo después de su entrega se deciden las estrategias de mantenimiento como afirma el administrador de uno de los proyectos:

La constructora prometió una cancha de tenis, de vóleibol, de básquet y un lago, además de una oficina, pero estas áreas corresponden a cesiones públicas que no entregarán hasta terminar el conjunto de proyectos, un proceso que puede tardar varios años y que no alcanzaremos a ver los residentes. Mientras tanto, la única cancha de futbol habilitada, se deteriora a pesar de que se creó una asociación para su mantenimiento de la que hacen parte todas las etapas.

Por otra, en referencia a las limitaciones para incluir dotacionales de carácter comercial, no solamente desde 
el planeamiento urbanístico, sino también desde el sistema fiscal. El conjunto es residencial es en principio no comercial e inhabilita al promotor del proyecto para proyectar recintos orientados a este propósito, incluso en proporciones reducidas. A pesar de ello, algunos hogares tienen su lugar de trabajo en las viviendas y entre ellas es posible encontrar algunas que ofrecen a los residentes del conjunto artículos de primera necesidad; actividades que pueden ser objeto de regulación por la Asamblea de Propietarios para garantizar condiciones de convivencia.

Sin embargo, esta condición origina un cambio de uso de la copropiedad, lo que conlleva a una elevación de las tarifas de servicios públicos y de las cargas impositivas a la copropiedad, razón por la cual las administraciones niegan cualquier posibilidad comercial o productiva en el conjunto. Superable con un tratamiento fiscal para cada unidad del proyecto en la que la participación en la copropiedad de cada propietario, no solamente se valore en función del tamaño de su propiedad, sino de la actividad que desarrolle.

Una forma de paliar las dificultades de acceso a los servicios especialmente de los primeros residentes en suelos periféricos urbanos es una mayor flexibilidad en los usos que pueden proponer los promotores urbanos, dejando como propone Ángel (2015) que el mercado haga lo que sabe hacer y que el estado, concentre su esfuerzo en la dotación de sistemas generales y en regular las obligaciones de dotación local garantizando la viabilidad de los emprendimientos urbanísticos.

\section{Conclusiones}

La oferta de equipamientos y servicios públicos y privados se genera a partir de tres (3) condiciones en la planeación local colombiana: primero, como resultado de los proyectos municipales contenidos el POT, segundo, a través de las cesiones, cuyo suelo pasa a manos públicas $y$, en tercer lugar, como resultado de las posibilidades generadas por la reglamentación de los usos del suelo.

La primera condición, se corresponde con las cargas generales que configuran el enlace regional de los sistemas estructurantes urbanos y su análisis, permite identificar dependencias funcionales. Así, se puede confirmar que los cuatro municipios del Corredor industrial y de servicios Bogotá-Facatativá [CVSO], especialmente Madrid y Mosquera, han conseguido algún grado de autosuficiencia por cuanto se consolida una oferta de trabajo y de servicios locales y regionales en ellos.

La segunda, asociada al desarrollo inmobiliario asegura suelo suficiente, para disponer de los soportes funcionales en los nuevos proyectos, imponiéndole al constructor cesiones públicas obligatorias. Los proyectos estudiados cumplen con ellas en su diseño, pero no en el avance de sus etapas que muestran un gran retraso que se suma a que las edificabilidades conseguidas, pueden superar las densidades poblacionales quebrando la relación de metros cuadrados de servicio por habitante, haciendo inalcanzables referentes de dotación como la meta nacional de $15 \mathrm{~m}^{2}$ de espacio público por habitante. De otra parte, el trámite para su entrega a los municipios, usualmente con la terminación de todas las etapas, implica un disfrute parcial de las áreas comunes de la etapa respectiva. Solo pleno, al transcurrir varios años de residencia.

Un comprador de vivienda supone que, con su transacción, es poseedor de un lugar de habitación que dispondrá de los servicios necesarios para habitarla. Con lo cual, para que una empresa pueda ofrecer en venta un proyecto de vivienda, debe asegurar la prestación de los servicios públicos domiciliarios básicos y con ello hacer entrega de las infraestructuras, redes y dispositivos para asegurar la disponibilidad permanente de agua potable, los sistemas de alcantarillado, recolección de basuras y energía eléctrica, así como de las obras para el acceso a los servicios domiciliarios de gas domiciliario, internet que serán ofrecidos por terceros a las unidades de vivienda, y adquiridos de manera optativa por ellas.

Pero la entrega tardía de las infraestructuras para los servicios ofrecidos en el proyecto para garantizar una residencia permanente, así como de los generados por la demanda de una población nueva en sus vecindades, retarda su goce efectivo. Debido a que los procesos de venta de la vivienda se realizan con años de antelación a su entrega a los propietarios y que las áreas que conforman las áreas comunes se entregan con un retraso respecto a las unidades de vivienda, no siempre se corresponde lo que estos propietarios reciben con las expectativas de lo que compraron. 
Otra fuente de conflicto es la reglamentación de mínimos no realistas a los que se ajustan los promotores que impide cuotas adecuadas de atención, como sucede con la insuficiencia de parqueaderos, o por cuenta de limitaciones fiscales, que obligan a las administraciones de los conjuntos a impedir la oferta de servicios por parte de los residentes en los proyectos que habitan.

Algunas constructoras permiten el usufructo progresivo de algunas áreas comunes antes de su entrega formal. Sin embargo, los plazos de entrega de cada servicio deberán ser exigibles para que los potenciales compradores tengan claro los servicios y condiciones en las que ocuparán sus inmuebles en la respectiva etapa de desarrollo, y no únicamente, las que tendrán con el abandono de las responsabilidades del constructor al terminar el proyecto.

Como resultado o no de las posibilidades de uso que permite la reglamentación urbanística y de manera simultánea con el desarrollo de los proyectos de vivienda, la iniciativa privada responde a la demanda residencial cotidiana en la vecindad inmediata al proyecto con una incipiente y elemental oferta miscelánea de servicios, que progresivamente con la habitación de otras etapas, se consolida y diversifica de manera tal, que los proyectos que muestran mayor ejecución corresponden a los de mayor diversidad en la oferta de servicios y con el aumento de las distancias, se incrementa su complejidad y especialización.

Sin embargo, más del $80 \%$ los servicios revisados en el estudio son compatibles con la actividad residencial y dada la cantidad de funciones comprometidas en este suelo, son sugerentes de flexibilizar la reglamentación de uso del suelo. Con ello, se puede favorecer la mezcla funcional, pero también la tipológica y socioeconómica, y mejorar la relación dotacional de soporte residencial al establecer rangos de cesiones públicas en función de la densidad; evitando así, la tendencia de zonificaciones exhaustivas basadas exclusivamente en los impactos urbanísticos y cuotas de cargas locales universales en función del área urbanizable de los proyectos, que se revelan insuficientes al no tener en cuenta el número de habitantes servidos e inequitativas al obligar iguales cesiones a diferentes magnitudes de aprovechamientos [B]

\section{Referencias}

Ángel, S. (2011). Planeta de Ciudades (Santiago Restrepo, trad.). Nueva York: Universidad de New York. https://doi.org/10.4067/s0250-71612017000100014

Boix, R. (2003): Redes de ciudades y externalidades [Tesis doctoral]. Universidad Autónoma de Barcelona. Recuperado de: http://www.tdx.cat/handle/10803/3995.

Cagmani R. (2002) On the concept of territorial competitiveness: sound or misleading? ERSA Conference, Dortmund. https://doi.org/10.1080/0042098022000027022

Cámara de Comercio de Bogotá CCB. (2015). Caracterización económica y empresarial de diecinueve municipios de Cundinamarca Informe Final Cualitativo. Bogotá: DC, Cámara de Comercio de Bogotá. Recuperado de: https://bibliotecadigital.ccb.org.co/bitstream/handle/ 11520/14584/caracterizacion\%20economica\%20y\%2 0empresarial\%20de\%2019\%20municipios.pdf?sequen ce
Cervio, A. L.y D'Hers, V. (2012). Cuerpos y sensibilidades en falta. Una aproximación a la noción de necesidad en contextos de segregación socio-espacial. En Las tramas del sentir. Ensayos desde una sociología de los cuerpos y las emociones, pp. 113-150. Buenos Aires, ESEditora.

Comité de Integración Territorial CIT. (2018). El Territorio de la Economía de Bogotá y la Región Vida Ampliada. Modelo Económico Territorial MOET. Bogotá, Centro de Pensamiento en Estrategias Competitivas (CEPEC). Universidad del Rosario.

Congreso de la Republica de Colombia (2001). Ley 675 de 2001, por medio de la cual se expide el régimen de propiedad horizontal. Diario Oficial No. 44.509

Congreso de la Republica de Colombia (1997). Ley 388 de Desarrollo Territorial. 
Dávila C. A., Munévar, C. y Giraldo, R. (2017). Territorios, margen y los mapas de la fragmentación. La creación de sujetos de desarrollo y sujetos de marginalidad. Civilizar Ciencias Sociales y Humanas, 17(32), 93-104. http://dx.doi.org/10.22518/16578953.820.

Esquivel-Cuevas, M., Hernández, O. y Garnica, R. (2014). Modelo de Accesibilidad Peatonal (MAP). Índice de Accesibilidad Peatonal a Escala Barrial. Bitácora Urbano Territorial, 23(2), 21-41. Recuperado en: https://www.redalyc.org/articulo.oa?id=7483087400 $\underline{4}$

García, J. E. (2016). Espacios de uso público y resolución de conflictos en la Jardín Balbuena. En Patricia Ramírez Kuri (Coord.), La reinvención del espacio público en la ciudad fragmentada, pp. 269-301. México: UNAM, Instituto de Investigaciones Sociales: Programa de Maestría y Doctorado en Urbanismo.

Hernández, A., Alguacil, J., Medina, M. y Moreno, C. (1997). La Ciudad de los ciudadanos. Madrid, Universidad Politécnica de Madrid UPM. Disponible en http://habitat.aq.upm.es/aciudad/lista 5.html

IDOM COLSUNTING (2018). Estudio del crecimiento y evolución de la huella urbana para los municipios que conforman el área Bogotá Región. Bogotá DC, Gobernación de Cundinamarca.

Instituto de Estudios Regionales y Urbanos [IERU] (1999). Formulación de normas de equipamiento urbano. Informe final. Caracas: Universidad Simón Bolívar. Recuperado de: http://www.habitur.grupos.usb.ve/Images/Normas\% 20de\%20Equip.\%20Urbano.\%20Doc.pdf

Isaza, J. I. (2008) Conurbación y Desarrollo Sustentable: Una Estrategia de Intervención para la Integración Regional. Caso: Primer Anillo Metropolitano BogotáSabana de Occidente [Tesis]. Maestría en Planeación Urbana y Regional. Pontificia Universidad Javeriana, Bogotá D.C. Disponible en: http://hdl.handle.net/10554/223

Munizaga Vigil, G. (2000). Macroarquitectura; tipologías y estrategias de desarrollo urbano. México: Alfaomega grupo editor.

Ortiz, C. y Garnica, R. (2008). La accesibilidad espacial en la definición de territorios inteligentes. Revista ACE (6), 759-776. Recuperado de: https://www.raco.cat/index.php/ACE/article/view/83 $\underline{564}$.
Preciado Beltrán, J. (2012). Prospectiva de expansión ambiental de Bogotá. En Ajustes ambientales al Plan de Ordenamiento Territorial del Distrito Capital. Bogotá: Secretaría Distrital de Ambiente SDP.

Sanabria, T. H. y Ramírez, J. F. (2019). De la intervención estatal excesiva a la regulación limitada en los aprovechamientos urbanísticos. Una aproximación alternativa al mercado inmobiliario. Questionar (6) (En prensa).

Sanabria, T. H. (2017). Modelo de evaluación del pleno aprovechamiento en distintos tipos de zonas urbanísticas. Un análisis de la eficiencia tipológica en Colombia [Tesis]. Doctorado en Gestión y Valoración Urbana y Arquitectónica, Departament de Tecnologia de l'Arquitectura, Universitá Politécnica de Catalunya, Barcelona, España. Disponible en: http://hdl.handle.net/2117/114226

Santos, Milton. (1997). Temica, Espap, Tempo. Globalizacao e meio temico-cientifico infmmbonal. Sao Paulo, Editora Hucitec.

Secretaría Distrital de Movilidad (2015). Encuesta de Movilidad de Bogotá DC. 2015. Cartilla Final. Secretaría Distrital de Movilidad SDM. Disponible en: https://drive.google.com/file/d/OByNoeWkPXuHpakp SeFVOdnBsQ3c/view

Secretaría Distrital de Planeación (2014). Región Metropolitana de Bogotá: Una visión de la ocupación del suelo. Bogotá SDP. Recuperado de: http://www.sdp.gov.co/sites/default/files/region_me tropolitana de bogota una vision de la ocupacion del suelo.pdf

Sobrino, J. (2005). Competitividad Territorial: ámbitos e indicadores de análisis. Economía, Sociedad y Territorio (Dossier Especial), 123-183. Recuperado de: http://www.redalyc.org/articulo.oa?id=11109906

Troncoso, J. y Marmolejo, C. (2010) De la accesibilidad a la funcionalidad del territorio: una nueva dimensión para entender la estructura urbano-residencial de las áreas metropolitanas de Santiago (Chile) y Barcelona (España). Revista de Geografía Norte Grande, (46), 527. http://dx.doi.org/10.4067/S071834022010000200001

Webber, M. (1970) Indagaciones sobre la estructura urbana. Barcelona: Gustavo Gilli.

Wikiproyecto Colombia. (2018). OpenStreetMap Wiki. Recuperado de: http://wiki.openstreetmap.org/w/index.php?title=ES: Wikiproyecto Colombia\&oldid=1604498. 